\title{
Pengaruh Pemanfaatan Abu Tumbuhan Perumpung Terhadap Peningkatan Kuat Tekan Beton K300
}

\author{
Ahmad Junaidi' ${ }^{1}$ R. Dewo Hiraliyamaesa Hariyanto \\ ${ }^{1}$ Program Studi Teknik Sipil, Universitas Muhammadiyah Palembang, Indonesia \\ 2Program Studi Teknik Sipil, Universitas Muhammadiyah Palembang, Indonesia \\ Email: 1junaidi.3537@gmail.com, ${ }^{2}$ dewo.hariyanto@gmail.com
}

\begin{abstract}
Perumpung (Eulalia japonica) is a wild plant that usually grows on the banks of river. The locals consider this plant as a waste/pest, but the authors are interested in researching perumpung because they are similar to bamboo, sugarcane and other fibrous plants. In this study, the authors aims to compare the compressive strength of normal concrete with the compressive strength of concrete added with Perumpung ash at 28-days-old K-300. The study used a cube-shaped test object $(15 \times 15 \times 15 \mathrm{~cm})$ with 6 samples for each condition. The total number of test objects is 48 , which consists of 8 conditions, namely normal conditions and $5 \%, 7.5 \%, 10 \%, 12.5 \%, 15 \%, 17.5 \%$ and $20 \%$ addition of perumpung ash by cement weight. The results obtained that the compressive strength of 28 -days-old concrete under normal conditions was $316,060 \mathrm{~kg} / \mathrm{cm} 2$ and the addition of $5 \%$ ash was $331.583 \mathrm{~kg} / \mathrm{cm} 2,7.5 \%$ was $337.181 \mathrm{~kg} / \mathrm{cm} 2,10 \%$ was $341.813 \mathrm{~kg} / \mathrm{cm} 2,12,5 \%$ is 347,045 $\mathrm{kg} / \mathrm{cm} 2,15 \%$ is $353,889 \mathrm{~kg} / \mathrm{cm} 2,17.5 \%$ is $311,160 \mathrm{~kg} / \mathrm{cm} 2$ and $20 \%$ is $298.44 \mathrm{~kg} / \mathrm{cm} 2$. From the results above it can be concluded that the addition of $15 \%$ Perumpung Ash to the concrete mixture increases the maximum characteristic concrete compressive strength by $353.889 \mathrm{~kg} / \mathrm{cm} 2$.
\end{abstract}

Keywords: Trunk Ash, Perumpung, K300

\section{PENDAHULUAN}

Tumbuhan perumpung (eulalia japonica) merupakan tanaman liar yang biasanya tumbuh di pinggiran sungai. Masyarakat sekitar menilai batang perumpung ini sebagai limbah atau hama, bahkan tumbuhan ini terkadang banyak tumbuh di pinggir jalan, sehingga terkadang tumbuhan ini menghalangi penglihatan para pengemudi yang melintas di daerah tersebut. Secara fisik tumbuhan ini punya kemiripan dengan dengan batang bambu, tebu dan pohon berserat lainnya, dengan batang yang terdiri dari ruas ruang dan bagian luarnya lebih keras dibanding bagian dalamnya. 


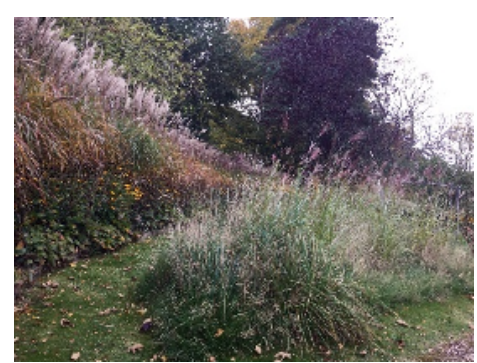

Gambar 1. Tumbuhan Perumpung (Eulalia Japonica)

Berdasarkan hasil pengujian yang dilakukan di Laboratorium Baristand Industri Palembang, bahwa abu dari tumbuhan ini mengandung kadar silika $\left(\mathrm{SiO}_{2}\right)$ yang cukup tinggi, yaitu 70,11\%. Berdasarkan dari data tersebut maka peneliti berupaya memanfaatkan abu tumbuhan ini pada campuran beton.

Untuk mengetahui seberapa besar atau seberapa banyak persentase campuran abu tumbuhan perumpung ini sehingga menghasilkan kuat tekan yang paling optimal pada umur beton beton 28 hari, maka penelitian ini bermaksud untuk memanfaatkan tumbuhan perumpung, sehingga dapat menimbulkan nilai ekonomis dari tumbuhan perumpung ini, serta untuk mengetahui pengaruh pemanfaatan abu tumbuhan perumpung terhadap kuat tekan beton dengan menggunakan variasi penambahan abu tumbuhan perumpung yang mengandung kadar Silika $\left(\mathrm{SiO}_{2}\right)$ ini terhadap campuran beton.

Beton adalah campuran agregat halus dan agregat kasar sebagai bahan pengisi. Ditambah semen dan air yang digunakan sebagai bahan pengikat baik dengan bahan tambah maupun tidak dengan bahan tambah [4][5]. Sekarang ini penggunaan beton banyak digunakan untuk sebagai konstruksi, misalnya jalan, jembatan, lapangan terbang, waduk, bendungan dan lainnya. Dengan melakukan analisa bahan maka dalam hal pembuatan beton harus lebih teliti dengan berbagai macam material-material yang digunakan dalam pembuatan tersebut, dikarenakan apabila suatu material dalam beton itu tidak bagus maka hasil dari beton tersebut tidak akan mencapai pada hasil yang diinginkan.

\subsection{Material Pembentuk Beton}

Semen merupakan salah satu bahan utama dalam pembuatan beton [1]. Semen adalah bahan yang mempunyai sifat adhesif maupun kohesif, yaitu bahan pengikat. Menurut Standar Industri Indonesia, SII 0013-1981, definisi semen portland adalah semen hidraulis yang dihasilkan dengan cara menghaluskan klinker yang terutama terdiri dari silikat-silikat kalsium yang bersifat hidraulis bersama bahanbahan yang digunakan yaitu gypsum. Didalam semen terdapat empat macam senyawa semen, dimana jumlah masing-masing senyawa seperti 


\section{Jurnal TEKNO}

(Civil Engineeering, Elektrical Engineeering and Industrial Engineeering)

Vol. 16, No : 1, April 2019 , p-ISSN:1907-5243, e-ISSN: 2655-8416

Tabel 1. . Empat Senyawa Utama dari Semen Portland

\begin{tabular}{lllll}
\hline Nama Oksida Utama & $\begin{array}{l}\text { Rumus } \\
\text { Empiris }\end{array}$ & Rumus Oksida & $\begin{array}{l}\text { Notasi } \\
\text { Pendek }\end{array}$ & $\begin{array}{l}\text { Kadar } \\
\text { Rata- } \\
\text { rata (\%) }\end{array}$ \\
\hline Trikalsium silikat & $\mathrm{Ca}_{3} \mathrm{SiO}_{5}$ & $3 \mathrm{CaO} . \mathrm{SiO}_{2}$ & $\mathrm{C}_{3} \mathrm{~S}$ & 50 \\
\hline Dikalsium silikat & $\mathrm{Ca}_{2} \mathrm{SiO}_{4}$ & $2 \mathrm{CaO} \cdot \mathrm{SiO}_{2}$ & $\mathrm{C}_{2} \mathrm{~S}$ & 25 \\
\hline Trikalsium aluminat & $\mathrm{Ca}_{3} \mathrm{Al}_{2} \mathrm{O}_{6}$ & $3 \mathrm{CaO} . \mathrm{Al}_{2} \mathrm{O}_{3}$ & $\mathrm{C}_{3} \mathrm{~A}$ & 12 \\
\hline Tetra kalsium alumina ferit & $2 \mathrm{Ca}_{2} \mathrm{AlFeO}_{5}$ & $4 \mathrm{CaO} \cdot \mathrm{Al}_{2} \mathrm{O}_{3} \cdot \mathrm{Fe}_{2} \mathrm{O}_{3}$ & $\mathrm{C}_{4} \mathrm{AF}$ & 8 \\
\hline Kalsium sulfat dihidrat (gypsum) & & $\mathrm{CaSO} \cdot 2 \mathrm{H}_{2} \mathrm{O}$ & $\mathrm{C}_{\mathrm{S}_{2}}$ & 3,5 \\
\hline
\end{tabular}

Sumber : [7]

Pembagian jenis atau tipe semen menurut peraturan beton 1989 (SKBI.1. 4.53.1989) dalam ulasannya dihalaman 1 , membagi semen portland menjadi lima jenis atau tipe yaitu [3] :

a. Semen Portland tipe I: Semen portland untuk konstruksi yang tidak memerlukan persyaratan khusus seperti jenis-jenis lainnya.

b. Semen Portland tipe II: Semen portland untuk konstruksi biasa dimana diinginkan perlawanan terhadap sulfat atau panas dan hidrasi yang sedang.

c. Semen Portland tipe III: Semen portland yang dalam penggunaannya memerlukan kekuatan awal yang tinggi dalam fase permulaan setelah pengikatan terjadi.

d. Semen Portland tipe IV: Semen portland yang portland yang dalam penggunaannya memerlukan panas hidrasi yang rendah.

e. Semen Portland tipe V: Semen portland yang dalam penggunaannya memerlukan ketahanan yang tinggi terhadap sulfat.

Agregat adalah butiran mineral yang berfungsi sebagai bahan pengisi dalam campuran mortar atau beton. Menurut ukurannya, agregat dibedakan menjadi dua golongan yaitu:

a. Agregat halus

Agregat halus adalah batuan yang lebih kecil dari 4,80 mm (4,75 mm) berdasarkan Standar ASTM.

b. Agregat kasar

Agregat kasar adalah batuan yang lebih besar dari 4,80 mm (4,75 mm) berdasarkan Standar ASTM.

Pada pengerjaan beton, air merupakan salah satu bahan yang diperlukan dalam pencampuran beton, karena mampu membantu mempercepat terjadinya proses kimia antara air dengan semen. Selain itu air juga berfungsi memudahkan pekerjaan pembuatan beton agar sesuai dengan bentuk yang diinginkan.

\subsection{Faktor Berpengaruh Pada Kuat Tekan Beton}

Kuat tekan beton bertambah tinggi dengan bertambahnya umur. Yang dimaksudkan umur disini dihitung sejak beton dicetak. Laju kenaikan kuat tekan 
beton mula-mula cepat, lama-lama laju kenaikan itu semakin lambat dan laju kenaikan tersebut menjadi relatif sangat kecil setelah berumur 28 hari, sehingga secara umum dianggap tidak naik lagi setelah berumur 28 hari. Oleh karena itu, sebagai standar kuat tekan beton (jika tidak disebutkan umur secara khusus) ialah kuat tekan beton pada umur 28 hari.

Tabel 2. . Rasio Kuat Tekan Beton pada Berbagai Umur

\begin{tabular}{llllllll}
\hline Umur Beton (hari) & 3 & 7 & 14 & 21 & 28 & 90 & 365 \\
\hline Semen Portland Biasa & 0,40 & 0,65 & 0,88 & 0,95 & 1,00 & 1,20 & 1,35 \\
\hline $\begin{array}{l}\text { Semen Portland dengan } \\
\text { Kekuatan Awal yang Tinggi }\end{array}$ & 0,55 & 0,75 & 0,90 & 0,95 & 1,00 & 1,15 & 1,20 \\
\hline
\end{tabular}

Sumber : [10]

Hal lain yang berpengaruh adalah Faktor Air Semen. Secara umum diketahui bahwa semakin tinggi nilai FAS semakin rendah mutu kekuatan beton. Namun demikian, nilai FAS, yang semakin rendah tidak selalu berarti bahwa kekuatan beton semakin tinggi. Nilai FAS yang rendah akan menyebabkan kesulitan dalam pekerjaan, yaitu kesulitan dalam pelaksanaan pemadatan yang pada akhirnya akan menyebabkan mutu beton menurun. Umumnya nilai FAS minimum yang diberikan sekitar 0,4 dan maksimum 0,65. Rata-rata ketebalan lapisan yang memisahkan antar partikel dalam beton sangat bergantung pada faktor air semen yang digunakan dan kehalusan butiran semennya. Untuk mengatasi kesulitan pengerjaan karena rendahnya nilai FAS ditambahkan bahan tambah " Admixture Concrete" yang menambah keenceran.

Faktor air semen yang diperlukan untuk mencapai kuat tekan rata-rata yang ditargetkan didasarkan pada hubungan kuat tekan dan faktor air semen yang diperoleh dari hasil penelitian lapangan sesuai dengan bahan dan kondisi pekerjaan yang diusulkan. Bila tidak tersedia data hasil penelitian sebagai pedoman, dapat digunakan (SNI, 1990: 6-8) [3].

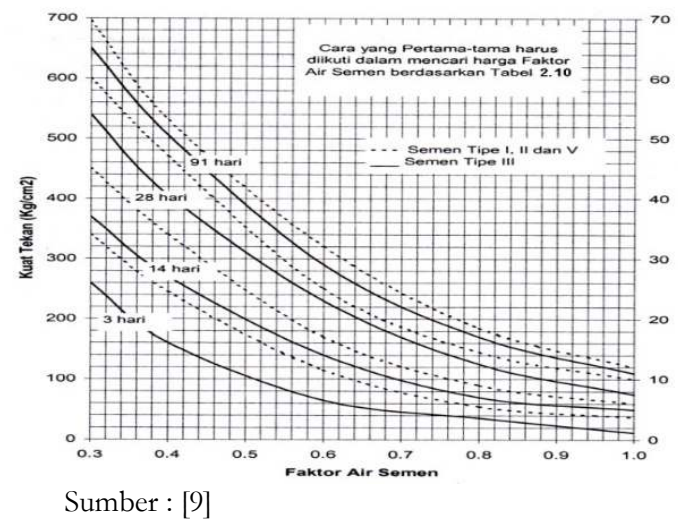

Gambar 2. Grafik Hubungan Kuat Tekan dan FAS untuk Benda Uji Kubus 
Proses hidrasi semen adalah proses untuk mempercepat pengeringan pada beton. Ketika air ditambahkan ke dalam campuran semen, proses kimiawi yang disebut hidrasi akan berlangung. Senyawa kimia di dalam semen akan bereaksi dengan air dan membentuk komponen baru.

Mekanisme hidrasi semen ada dua, yaitu mekanisme larutan dan mekanisme padat. Pada mekanisme larutan, zat yang direaksikan larutan dan menghasilkan ion dalam larutan. Ion-ion ini kemudian akan bergabung sehingga menghasilkan zat yang menggumpal (flocculate). Pada semen, karena daya larut senyawa yang ada kecil maka hidrolisis lebih dominan daripada larutan.

Tabel 3. Reaksi Hidrasi Senyawa Semen

\begin{tabular}{|c|c|}
\hline Senyawa yang Bereaksi & Komponen yang Dihasilkan \\
\hline Trikalsium silikat + Air & Gel tobermorit + Kalsium hidroksida \\
\hline Dikalsium silikat + Air & Gel tobermorit + Kalsium hidroksida \\
\hline $\begin{array}{l}\text { Tetrakalsium aluminoferrit }+ \text { Air }+ \\
\text { Kalsium hidroksida }\end{array}$ & Kalsium aluminoferrit hidrat \\
\hline $\begin{array}{l}\text { Tetrakalsium aluminat }+ \text { Air }+ \\
\text { Kalsium hidroksida }\end{array}$ & Tetrakalsium aluminat hidrat \\
\hline $\begin{array}{l}\text { Tetrakalsium aluminat }+ \text { Air }+ \\
\text { Kalsium }\end{array}$ & Kalsium monosulfoaluminate \\
\hline
\end{tabular}

\section{METHODS}

Dalam pelaksanaan pembuatan beton berbentuk kubus dalam kondisi normal dan tambahan abu batang perumpung, perlu disiapkan terlebih dahulu alat dan bahan yang akan digunakan. Adapun beberapa langkah yang harus dilakukan adalah sebagai berikut:

a. Pengujian kandungan $\mathrm{SiO} 2$ pada abu tanaman perumpung

b. Uji material

c. Pembuatan benda uji

Kadar silika (SiO2) yang terkandung dalam abu batang perumpung adalah sebesar 70,11\% berdasarkan hasil pengujian Laboratorium Baristand Industri Palembang.

Pengujian material mengacu pada spesifikasi dalam SNI 03-1750-1990 dimana agregat kasar dan halus harus berkualitas baik, tidak terkontaminasi dan harus memiliki susunan besar butir (gradasi) serta kelembaban yang seragam. Benda uji yang dibuat pada penelitian ini sebanyak 48 buah dengan 8 kondisi, tiap kondisi terdiri 6 benda uji ukuran $(15 \mathrm{~cm} \times 15 \mathrm{~cm} \times 15 \mathrm{~cm})$ yaitu:

1. Kondisi beton normal,

2. Kondisi beton normal dengan penambahan abu perumpung $5 \%$, 
(Civil Engineeering, Elektrical Engineeering and Industrial Engineeering)

Vol. 18, No : 2, Oktober 2021, p-ISSN:1907-5243, e-ISSN: 2655-8416

3. Kondisi beton normal dengan penambahan abu perumpung $7,5 \%$

4. Kondisi beton normal dengan penambahan abu perumpung $10 \%$

5. Kondisi beton normal dengan penambahan abu perumpung $12,5 \%$

6. Kondisi beton normal dengan penambahan abu perumpung $15 \%$

7. Kondisi beton normal dengan penambahan abu perumpung $17,5 \%$

8. Kondisi beton normal dengan penambahan abu perumpung $20 \%$

Sebelum dilakukan pengujian kuat tekan pada benda uji, benda uji tersebut ditimbang terlebih dahulu, kemudian dilakukan pengujian kuat tekan pada benda uji tersebut, untuk mendapatkan nilai kuat tekannya.

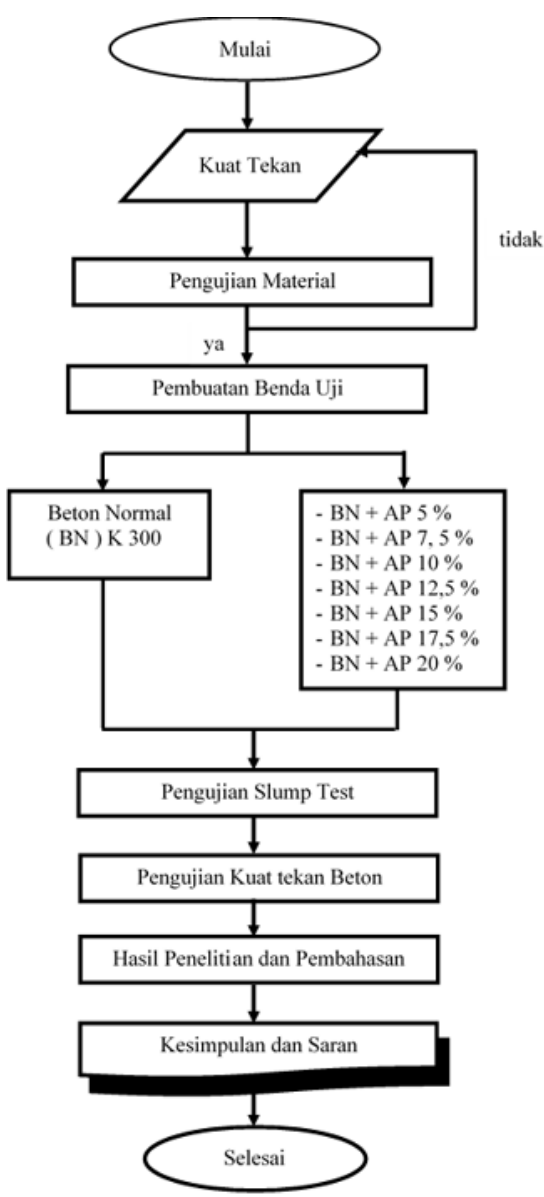

Gambar 3. Bagan Alir Penelitian

\section{HASIL DAN PEMBAHASAN}

Dari pengujian kuat tekan beton umur 28 hari yang dilakukan di Laboratoriun Teknologi Beton Fakultas Teknik Universitas Muhannadiyah Palembang, 


\section{Jurnal TEKNO}

(Civil Engineeering, Elektrical Engineeering and Industrial Engineeering)

Vol. 16, No : 1, April 2019 , p-ISSN:1907-5243, e-ISSN: 2655-8416

didapatlah data nilai deviasi standar dan kuat tekan beton karakterisitik pada berbagai kondisi.

Tabel 4. Hasil Pengujian Kuat Tekan Beton Umur 28 Hari

\begin{tabular}{|c|c|c|c|c|c|c|c|c|c|c|}
\hline \multirow{2}{*}{ No. } & \multirow{2}{*}{ Kondisi } & \multirow{2}{*}{$\begin{array}{l}\text { Umur } \\
\text { (hari) }\end{array}$} & \multirow{2}{*}{$\begin{array}{l}\text { Luas } \\
\left(\mathrm{cm}^{2}\right)\end{array}$} & \multirow{2}{*}{$\begin{array}{c}\text { Berat } \\
\text { (kg) }\end{array}$} & \multicolumn{2}{|c|}{ Beban } & \multirow{2}{*}{$\begin{array}{c}\sigma \\
\text { Hancur } \\
\left(\mathrm{kg} / \mathrm{cm}^{2}\right)\end{array}$} & \multirow{2}{*}{$\begin{array}{c}\sigma \\
\text { Hancur } \\
\text { Rata-rata } \\
\left(\mathrm{kg} / \mathrm{cm}^{2}\right)\end{array}$} & \multirow{2}{*}{$\begin{array}{c}\text { Deviasi } \\
\text { Standar } \\
\text { (S) }\end{array}$} & \multirow{2}{*}{$\begin{array}{c}\text { Kuat Tekan } \\
\text { Beton } \\
\text { Karakteristik } \\
\left(\mathrm{kg} / \mathrm{cm}^{2}\right)\end{array}$} \\
\hline & & & & & Kn & $\mathrm{Kg}$ & & & & \\
\hline 1. & \multirow{6}{*}{$\begin{array}{l}\text { Beton } \\
\text { Normal }\end{array}$} & 28 & 225 & 7,65 & 723,79 & 73755 & 327,8 & \multirow{6}{*}{327,6} & \multirow{6}{*}{7,036} & \multirow{6}{*}{316,060} \\
\hline 2. & & 28 & 225 & 7,6 & 733,73 & 74767,5 & 332,3 & & & \\
\hline 3. & & 28 & 225 & 7,5 & 713,19 & 72675 & 323,0 & & & \\
\hline 4. & & 28 & 225 & 7,75 & 701,27 & 71460 & 317,6 & & & \\
\hline 5. & & 28 & 225 & 7,3 & 722,25 & 73597,5 & 327,1 & & & \\
\hline 6 & & 28 & 255 & 7,7 & 745,87 & 76005 & 337,8 & & & \\
\hline 1. & \multirow{6}{*}{$\begin{array}{c}\text { Beton } \\
\text { Normal } \\
+ \\
\text { Perumpung } \\
5 \%\end{array}$} & 28 & 225 & 7,85 & 748,08 & 76230 & 338,8 & \multirow{6}{*}{338,18} & \multirow{6}{*}{4,022} & \multirow{6}{*}{331,583} \\
\hline 2. & & 28 & 225 & 7,5 & 761,33 & 77580 & 344,8 & & & \\
\hline 3. & & 28 & 225 & 7,8 & 739,91 & 75397,5 & 335,1 & & & \\
\hline 4. & & 28 & 225 & 7,7 & 737,04 & 75105 & 333,8 & & & \\
\hline 5. & & 28 & 225 & 7,7 & 742,56 & 75667,5 & 336,3 & & & \\
\hline 6. & & 28 & 225 & 7,3 & 751,39 & 76567,5 & 340,3 & & & \\
\hline 1. & \multirow{6}{*}{$\begin{array}{c}\text { Beton } \\
\text { Normal } \\
+ \\
\text { Perumpung } \\
7,5 \%\end{array}$} & 28 & 225 & 7,5 & 766,63 & 78120 & 347,2 & \multirow{6}{*}{342,73} & \multirow{6}{*}{3,383} & \multirow{6}{*}{337,181} \\
\hline 2. & & 28 & 225 & 7,4 & 761,77 & 77625 & 345,0 & & & \\
\hline 3. & & 28 & 225 & 7,5 & 758,02 & 77242,5 & 343,3 & & & \\
\hline 4. & & 28 & 225 & 7,4 & 757,13 & 77152,5 & 342,9 & & & \\
\hline 5. & & 28 & 225 & 7,5 & 745,43 & 75960 & 337,6 & & & \\
\hline 6. & & 28 & 225 & 7,5 & 751,61 & 76590 & 340,4 & & & \\
\hline 1. & \multirow{6}{*}{$\begin{array}{c}\text { Beton } \\
\text { Normal } \\
+ \\
\text { Perumpung } \\
10 \%\end{array}$} & 28 & 225 & 7,5 & 754,48 & 76882,5 & 341,7 & & & \\
\hline 2. & & 28 & 225 & 7,6 & 766,85 & 78142,5 & 347,3 & & & \\
\hline 3. & & 28 & 225 & 7,3 & 757,13 & 77782,5 & 345,7 & & & \\
\hline 4. & & 28 & 225 & 7,3 & 763,32 & 77242,5 & 350,6 & 346,95 & 3,132 & 341,813 \\
\hline 5. & & 28 & 225 & 7,4 & 771,71 & 78637,5 & 349,5 & & & \\
\hline 6. & & 28 & 225 & 7,3 & 766,63 & 78120 & 346,9 & & & \\
\hline 1. & & 28 & 225 & 7,5 & 789,81 & 80482,5 & 357,7 & & & \\
\hline 2. & Beton & 28 & 225 & 7,5 & 773,69 & 78840 & 350,4 & & & \\
\hline 3. & Norn & 28 & 225 & 7,4 & 802,62 & 81787,5 & 363,5 & 355,06 & 4,887 & 347,045 \\
\hline 4. & $\stackrel{+}{+}$ & 28 & 225 & 7,5 & 777,674 & 79245 & 352,2 & & & \\
\hline 5. & Perumpung & 28 & 225 & 7,65 & 783,41 & 79830 & 354,8 & & & \\
\hline 6. & & 28 & 225 & 7,5 & 776,79 & 79155 & 351,8 & & & \\
\hline 1. & & 28 & 225 & 7,4 & 802,62 & 81787,5 & 363,5 & & & \\
\hline 2. & Beton & 28 & 225 & 7,6 & 782,97 & 79785 & 354,6 & & & \\
\hline 3. & Normal & 28 & 225 & 7,75 & 789,42 & 81360 & 361,6 & 359,28 & 3,287 & 353,889 \\
\hline 4. & & 28 & 225 & 7,5 & 791,14 & 80617,5 & 358,3 & & & \\
\hline 5. & rumpung & 28 & 225 & 7,5 & 796,66 & 81180 & 360,8 & & & \\
\hline 6. & & 28 & 225 & 7,4 & 788,05 & 80302,5 & 356,9 & & & \\
\hline 1. & Beton & 28 & 225 & 7,6 & 720,70 & 73440 & 326,4 & & & \\
\hline 2. & Normal & 28 & 225 & 7,5 & 696,85 & 71010 & 315,6 & 320,1 & 5,451 & 311,160 \\
\hline 3. & + & 28 & 225 & 7,5 & 708,34 & 72180 & 320,8 & & & \\
\hline
\end{tabular}




\section{Jurnal TEKNO}

(Civil Engineeering, Elektrical Engineeering and Industrial Engineeering)

Vol. 18, No : 2, Oktober 2021 , p-ISSN:1907-5243, e-ISSN: 2655-8416

\begin{tabular}{|c|c|c|c|c|c|c|c|c|c|c|}
\hline 4. & Perumpung & 28 & 225 & 7,65 & 718,94 & 73260 & 325,6 & & & \\
\hline 5. & $17,5 \%$ & 28 & 225 & 7,5 & 705,91 & 71932,5 & 319,7 & & & \\
\hline 6. & & 28 & 225 & 7,5 & 690,01 & 70312,5 & 312,5 & & & \\
\hline 1. & & 28 & 225 & 7.6 & 670,14 & 68287,5 & 303,5 & & & \\
\hline 2. & Beton & 28 & 225 & 7,5 & 673,23 & 68602,5 & 304,9 & & & \\
\hline 3. & Normal & 28 & 225 & 7,6 & 665,28 & 67792,5 & 301,3 & 303,26 & 2,939 & 298,44 \\
\hline 4. & + & 28 & 225 & 7,5 & 658,88 & 67140 & 298,4 & & & \\
\hline 5. & Perumpung & 28 & 225 & 7,4 & 673,89 & 68670 & 305,2 & & & \\
\hline 6. & & 28 & 225 & 7,7 & 676,32 & 68917,5 & 306,3 & & & \\
\hline
\end{tabular}

Hasil pengujian kuat tekan beton umur 28 hari pada tabel 1 diatas, dirangkum dalam grafik kuat tekan beton karakteristik umur 28 hari

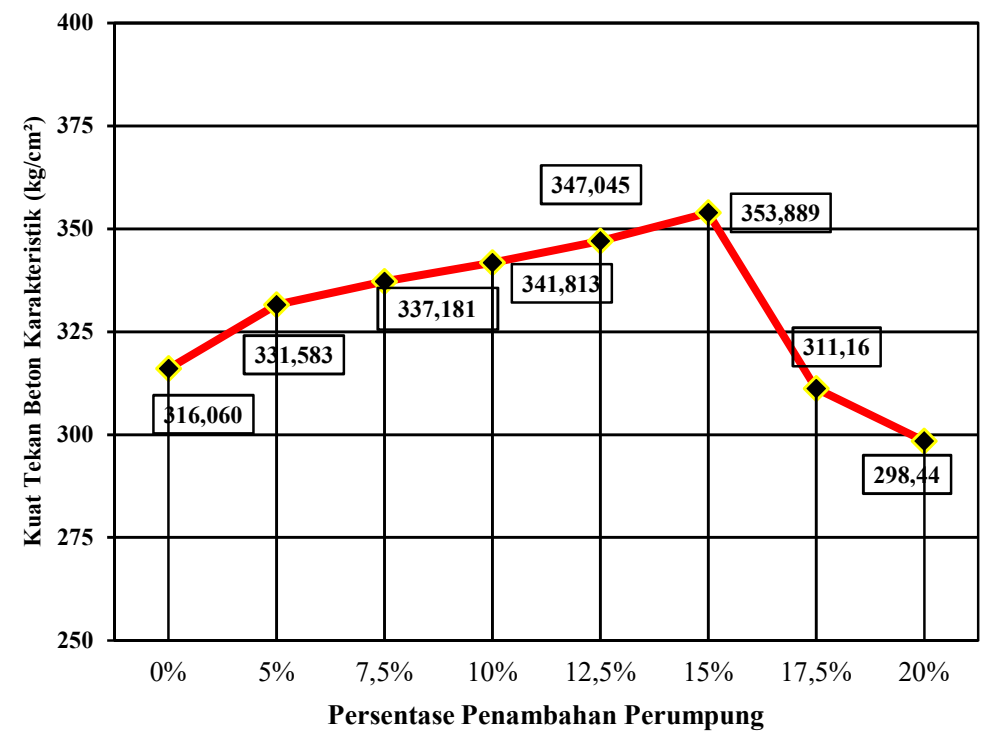

Gambar 4. Grafik Peningkatan Kuat Tekan Beton

Dari grafik dapat dilihat bahwa dengan penambahan abu Perumpung pada campuran beton dapat meningkatkan kuat tekan beton karakteristik. Dimana pada saat kondisi beton normal kuat tekan beton karakteristik 316,060 kg/ $\mathrm{cm} 2$ dan, pada kondisi beton normal dengan penambahan Perumpung 5\% didapat kuat tekan beton karakteristik sebesar $331,583 \mathrm{~kg} / \mathrm{cm} 2$. Pada kondisi beton normal dengan penambahan Perumpung 7,5\% diperoleh kuat tekan beton karakteristik sebesar 337,181 $\mathrm{kg} / \mathrm{cm} 2$. Pada kondisi beton normal dengan penambahan Perumpung 10\% diperoleh kuat tekan beton karakteristik sebesar 341,813 $\mathrm{kg} / \mathrm{cm} 2$. Pada kondisi beton normal dengan penambahan Perumpung $12,5 \%$ didapat kuat tekan beton karakteristik sebesar $347,045 \mathrm{~kg} / \mathrm{cm} 2$, . Pada kondisi beton normal dengan penambahan Perumpung 15\% diperoleh kuat tekan beton karakteristik sebesar 353,889 $\mathrm{kg} \mathrm{cm} 2$, kondisi ini menunjukkan kondidi yang paling optimum dengan peningkatan sebesar $11,968 \%$ dari beton normal. Pada kondisi 
beton normal dengan penambahan Perumpung 17,5\% didapat kuat tekan beton karakteristik sebesar $311,160 \mathrm{~kg} / \mathrm{cm} 2$ dan pada kondisi beton normal dengan penambahan Perumpung 20\% diperoleh kuat tekan beton karakteristik sebesar $298,44 \mathrm{~kg} / \mathrm{cm} 2$.

Peningkatan kuat tekan dengan adanya penambahan abu tumbuhan perumpung tersebut terjadi karena kapur bebas yang berasal dari reaksi semen normal diikat oleh $\mathrm{SiO}_{2}$ yang berasal dari abu tumbuhan perumpung tersebut, reaksi inilah yang kemudian akan mengisi rongga-rongga yang ada akibat reaksi kapur bebas pada beton normal.

Pelekatan antara mortar dengan agregat terjadi proses hidrasi :

$$
\text { Semen }+ \text { Air } \rightarrow \text { C-S-H }+\mathrm{Ca}(\mathrm{OH})_{2}+\text { Alumina }
$$

Dengan penambahan Perumpung yang mengandung Silika dioksida $\left(\mathrm{SiO}_{2}\right)$ maka menghasilkan reaksi C-H-S gel lebih stabil.

$$
\mathrm{Ca}(\mathrm{OH})_{2}+\mathrm{SiO}_{2}+\mathrm{H} 2 \mathrm{O} \rightarrow \mathrm{C}-\mathrm{H}-\mathrm{S} \text { gel lebih stabil. }
$$

C-H-S lebih stabil akan meningkatkan daya lekat antara pasta semen dengan agregat sehingga menambah kekuatan beton.

Sedangkan untuk penambahan Perumpung 17,5\%, dan 20\%, mengalami penurunan kuat tekan beton karateristik dari beton optimum. Hal ini terjadi karena $\mathrm{SiO}_{2}$ yang tidak mampu lagi bereaksi dengan kapur bebas yang dihasilkan dari sisa reaksi normal semen, hal inilah yang menyebabkan kuat tekannya kembali turun dibandingkan dengan penambahan abu tanaman perumpung sebesar $15 \%$.

\section{KESIMPULAN}

Setelah dilakukan terhadap benda uji dalam 8 kondisi pengujian dengan menggunakan abu tanaman perumpung sebagai bahan tambah pada campuran beton dan pengujiannnya dilakukan pada umur beton 28 hari, didapatlah kesimpulan bahwa dalam penggunaan bahan tambah abu batang perumpung, cukup menggunakan penambahan abu batang perumpung 15\% dari berat semen yang digunakan sehingga didapatkan kuat tekan beton karateristik sebesar 353,889 $\mathrm{kg} / \mathrm{cm}^{2}$ yang mengalami peningkatan sebesar $11,968 \%$ dari kuat tekan beton karakteristik dalam kondisi normal, serta diketahui bahwa semakin banyak penambahan abu batang perumpung dalam campuran beton, nilai slump yang dihasilkan akan semakin kecil sehingga mempengaruhi adukan campuran beton akan menjadi kental.

Diperlukan penelitian lanjutan untuk memanfaatkan abu tumbuhan perumpung, pengujian beton sebaiknya diperbanyak pada beton umur 3, 7, dan 21 
hari. Diperlukan pula jumlah sampel yang lebih banyak agar didapat hasil yang lebih akurat. Untuk pembakaran tumbuhan perumpung pada penelitian selanjutnya lebih baik divariasikan suhu dan waktu pembakarannya sehingga didapatkan kondisi yang paling optimum dalam menghasilkan kandungan $\mathrm{SiO}_{2}$.

\section{REFERENSI}

[1] A. E. Sutrisno dan D. Kartikasari. "Pengaruh Penambahan Abu Jerami Padi Terhadap Kuat Tekan Beton”. CIVILLa, vol. 2, No. 2, pp. 63-70, 2017. https://doi.org/10.30736/cvl.v2i2.74

[2] Direktorat Jenderal Cipta Karya Departemen Pekerjaan Umum. 1971. Peraturan Beton Bertulang Indonesia N. 1-2. Penerbit Yayasan LPMB. Bandung.

[3] Direktorat Jenderal Cipta Karya Departemen Pekerjaan Umum. 1990. Tata Cara Pembuatan Rencana Campuran Beton Normal SK SNI T-15-1990-03. Bandung.

[4] K. Wulandari dan D. Kartikasari. "Studi Pencampuran Serat Eceng Gondok Pada Campuran Beton Dengan Penggunaan Agregat Kasar Dari Kecamatan Mantup". UKaRsT, vol. 3, No. 1 (2019): 18-27. http://dx.doi.org/10.30737/ukarst.v3i1.348

[5] M. R. A. Saputro dan R. Hepiyanto. "Penambahan Serbuk Limbah Batu Kumbung Pada Campuran Beton”. CIVILLa, vol. 3, No. 1 (Maret 2018): 116-123.

[6] N. F. Cholida, Purwanto and H. Purwanti. "Investigation on the Compressive Strength of Gunny Sack Fiber Concrete under High-Temperatures”. Journal of Advanced Civil and Environmental Engineering 3, No. 1 (March 2020): 27-35. http://dx.doi.org/10.30659/jacee.3.1.27-35

[7] N. Paul dan Antoni. 2007. Teknologi Beton. Penerbit Andi Yogyakarta. Yogyakarta

[8] R. R. Dhana. "Analisis Pengaruh Pemakaian Material Kerikil Gunung Kecamatan Mantup dan Serat Alami Eceng Gondok Terhadap Kuat Tekan dan Kuat Lentur Beton”. CIVILLa 4, No. 1 (Maret 2019): 198-205.

[9] T. Mulyono. 2004. Teknologi Beton. Penerbit Andi Offset. Yogyakarta

[10] T. Kardiyono. 2007. Teknologi Beton : Buku Ajar. Penerbit Fakultas Teknik UGM. Yogyakarta 